\section{Migración, escuela y territorio. Experiencias del espacio dejado y el espacio habitado en contextos comunitarios y escolares}

- Verónica Hendel y Gabriela Novaro
Palabras clave:

Migración, escuela, territorio, experiencias, inclusión-exclusión.
Migration, school and territory. Experiences of left space and inhabited space in community and school contexts

\footnotetext{
Abstract

In this text we address the experiences of territory among migrants from Bolivia who live in two locations of Buenos Aires Province. We dwell on the way in which migrants and their descendants experience the relationship with the country of origin (the space left); in particular, we focus on the mobility between "here" and "there" and how this mobility crosses generational relations and translates into collective
}

Keywords:

Migration, school, territory, experiences, inclusion-exclusion. 
projects. We also analyze the relationship that the Bolivian population builds with the space that currently inhabits in Buenos Aires, analyzing the representations about inhabited space.

We then relate these ways of inhabiting space in community contexts with the ways of experiencing it in school situations. Work in schools allows us to affirm that school forms of representing space, although they have been revised in a context of discourses of inclusion and interculturality, are still traversed by traditional ways of thinking about the national, the territory and the borders. The experiences of space expressed at school are in tension with the transnational condition of a large part of the children and young people, although it is also possible to find valuable attempts to reformulate the ways of relating with migrant population.

\section{Introducción}

Las políticas y debates educativos en Argentina han incluido explícitamente la temática de la interculturalidad hace alrededor de dos décadas. Los enfoques interculturales instalaron la necesidad de repensar la situación educativa de la población indígena. Sin embargo, distintos trabajos muestran cómo la inclusión de múltiples colectivos y niveles educativos en las propuestas y los debates sobre la interculturalidad continúa siendo una deuda pendiente (Hecht, García Palacios, Enriz \& Diez, 2015; Novaro, 2016; Novaro \& Diez, 2011; Thisted, 2014). Es decir, ha habido avances, pero también muchas limitaciones. Desde hace varios años venimos sosteniendo que los migrantes latinoamericanos son uno más de los colectivos a sumar en una propuesta de interculturalidad que desafíe los mandatos y cánones tradicionales de la escuela: en ellos se focalizan las referencias de este trabajo.

En este artículo nos centramos en algunas particularidades de los procesos formativos familiares y comunitarios vinculados a las experiencias territoriales de una población en particular (migrantes procedentes de Bolivia y sus descendientes); buscamos asimismo poner estos procesos en relación con situaciones escolares que atraviesan los mismos colectivos. Desde este recorte, el objetivo último de este trabajo es advertir sobre el modo en que las experiencias, los procesos de identificación y las proyecciones a futuro de este grupo migrante dialogan y entran en tensión con los dispositivos y mandatos escolares.

El texto se centra en las experiencias del espacio/territorio de los migrantes procedentes de Bolivia que habitan dos localidades de la provincia de Buenos Aires, aborda cómo esta cuestión atraviesa las relaciones generacionales en contextos familiares y comunitarios y la articulación de las experiencias del "espacio dejado" (Bolivia) y el "espacio habitado" (Argentina) con los procesos de identificación. Nos interesa particularmente centrarnos en el modo en que los jóvenes son interpelados y en los sentimientos de pertenencia o extranjeridad que expresan. En ellos se advierten los dilemas asociados a asumir una nacionalidad y vivir en un territorio distinto al que, en gran medida, marca la pertenencia del grupo familiar. A continuación, realizamos un contrapunto con las representaciones y experiencias del territorio en las escuelas secundarias de la localidad.

Entre las múltiples dimensiones para abordar esta problemática, es necesario realizar algunas aclaraciones iniciales en torno a tres aspectos: la complejidad de los procesos de identificación en el colectivo con el que trabajamos, la centralidad del territorio como aspecto de las experiencias que atraviesa fuertemente las relaciones generacionales, los desafíos que estas cuestiones plantean al sistema educativo en la construcción de una propuesta intercultural e inclusiva tanto a nivel de las relaciones como de los modelos de identificación y los conocimientos que propicia. 
En los colectivos migrantes bolivianos los procesos de identificación se encuentran atravesados por dimensiones étnicas y nacionales que interpelan los modos tradicionales de identificación nacional que el sistema educativo ha propuesto y promovido históricamente. Nos preguntamos en este trabajo si en las escuelas donde realizamos el trabajo de campo, caracterizadas por un alto componente de población boliviana y descendiente, esta matriz se ve modificada o tensionada o sigue primando la concepción que asocia, de modo excluyente, las nociones de territorio, Estado y nación.

La movilidad constituye un aspecto central de las experiencias del territorio de los colectivos migrantes. En el marco de esas experiencias, los territorios de origen y destino tienen gran relevancia para comprender las marcas de identidad del grupo. Estas marcas atraviesan y distinguen las relaciones generacionales de quienes han vivido diferentes vínculos con esos espacios.

En el sistema educativo, a lo largo de la última década las nociones de espacio y territorio han sido revisadas en el marco de los documentos curriculares. Sin embargo, a partir de diversos trabajos y de nuestros propios registros de campo se observa cierta persistencia de enfoques tradicionales. Es nuestra intención, por ello, focalizar en dos aspectos donde la ampliación de la interculturalidad continúa siendo una deuda del sistema educativo: la problematización de los procesos de legitimación de saberes y el nivel secundario. El centramiento en este nivel educativo se fundamenta en que el mismo constituye el trayecto en que más claramente desciende el porcentaje de escolarización de la población boliviana. ${ }^{1}$ La escolarización secundaria, asimismo, representa un nivel históricamente selectivo y continúa, al día de hoy, poco permeable a los enfoques interculturales. También debemos tener presente que, desde sus inicios, la escuela secundaria estuvo signada por el mandato de constituirse en un paso fundamental para el ascenso social de sectores medios y medios bajos y que la sanción de su obligatoriedad, en el año 2006, planteó al nivel el desafío de albergar en sus aulas a jóvenes históricamente excluidos de ellas, entre otros, los migrantes latinoamericanos.

En las escuelas donde trabajamos advertimos distancias entre las experiencias del territorio de las familias migrantes y los presupuestos y paradigmas escolares tradicionales desde los que nación y territorio aparecen como un par incuestionado. Sin embargo, también encontramos interesantes replanteamientos en muchos actores escolares que se traducen en iniciativas fragmentadas, pero sostenidas de reformular las formas de concebir el territorio y abrir la escuela hacia el afuera y las fronteras de la nación hacia muchas naciones. El recorrido por las situaciones escolares se orienta a partir de la pregunta acerca de si las escuelas funcionan como lugares de imposición de lo nacionalargentino en territorios que en muchos sentidos podrían definirse como binacionales o se constituyen en un espacio de disputa identitaria.

\section{Migración y prácticas transnacionales en dos localidades del Gran Buenos Aires: desafíos a la inclusión e interpelaciones a la interculturalidad}

Las reflexiones de este artículo se sostienen, como decíamos, en la investigación en dos localidades de la provincia de Buenos Aires con alto componente de población proveniente de Bolivia: Escobar y Tres de Febrero. En los dos casos, además, los descendientes argentinos de padres bolivianos constituyen una parte importante de la población y sobre todo de las escuelas secundarias donde trabajamos.
1. Mientras la escolarización hasta los catorce años se encuentra prácticamente universalizada entre la población boliviana, el porcentaje de asistencia de los jóvenes bolivianos entre los catorce y diecinueve años desciende significativamente (Cerruti \& Binstock, 2012). 
2. En textos anteriores sistematizamos información y reflexiones sobre las escuelas primarias de la localidad (Novaro, 2014, 2015). Desde el año 2016 desarrollamos nuestra investigación en las escuelas secundarias cuyos edificios son contiguos a las primarias donde habíamos trabajado previamente.
En Escobar, la investigación se focaliza en el barrio Lambertuchi, ubicado a tres kilómetros del centro. Algunos vecinos definen este espacio como "barrio boliviano" (si bien lo mismo no corresponde a la nominación oficial, ni el modo en que el barrio figura en los relevamientos censales). Este trabajo se desarrolla desde el año 2010 en contextos familiares, comunitarios y escolares. ${ }^{2}$ En Tres de Febrero, la indagación se focaliza en Ciudadela, ubicada al sur del distrito y lindante con el barrio porteño de Liniers. Este trabajo se inició en el año 2017 y, hasta el momento, se desarrolló con mayor profundidad en contextos escolares. Ambas investigaciones se sostienen en el registro de numerosas situaciones de interacción, la reconstrucción de trayectorias biográficas, entrevistas y charlas informales y acompañamiento de situaciones escolares (clases, ingresos, fiestas, reuniones, etcétera). Esta información se complementa con el registro y análisis de documentos y datos estadísticos nacionales, provinciales y de las localidades donde trabajamos.

En ambas localidades se registra la desigualdad en el acceso al territorio y la vivienda de la población boliviana (situaciones de pobreza, limitaciones en los servicios de infraestructura, etcétera). No obstante, la dinámica migratoria y poblacional presenta particularidades en cada localidad. En Escobar los migrantes proyectan, por lo general, la permanencia; las organizaciones de migrantes manejan recursos económicos y políticos, tienen muchos años y un importante poder de convocatoria; en Ciudadela -Tres de Febrero- convive un sector de población migrante de larga data (década de 1980) y otro más numeroso que experimenta el barrio como una zona de habitación temporaria o de tránsito; aquí la presencia de organizaciones de migrantes es más reciente. A diferencia de Escobar, Ciudadela es un barrio netamente urbano.

En Escobar, la migración procedente de Bolivia llega, fundamentalmente, en la década de 1980 desde localidades cercanas a Potosí. Se inserta en principio en la actividad hortícola y en años posteriores se vincula también al comercio. Otra particularidad de la zona es el avance de los barrios privados y el gran crecimiento de la población. En Escobar la Colectividad Boliviana (CBE) comenzó a organizarse desde el año 1986, si bien se institucionalizó en 1991. Hoy nuclea alrededor de mil miembros (de acuerdo a apreciaciones de sus referentes y listados de socios) y es propietaria de importantes edificios vinculados a la comercialización de productos frutihortícolas y vestimenta. También es relevante el peso de la CBE en la política local y su protagonismo en la organización de múltiples eventos sociales, en particular el festejo de celebraciones cívicas bolivianas

En el caso de Tres de Febrero, el barrio en el cual trabajamos, Ciudadela, linda con el barrio de Liniers de la Ciudad Autónoma de Buenos Aires, conformando una gran zona con una importante comunidad boliviana desde la década de 1990. Según nuestros registros de campo, la mayor parte de esta población proviene de Potosí y, en menor medida, de Cochabamba y Santa Cruz. Existe una coordinadora (Coordinadora de la Colectividad Boliviana en Liniers) que cuenta con un centro médico propio (Centro Médico Santiago Apóstol) y tiene injerencia en la organización de la Feria Boliviana o Mercado Andino y en celebraciones comunitarias tales como la Procesión por la Virgen de Urkupiña.

Es importante destacar que, en ambas localidades, además, se registran fuertes lazos económicos y políticos con Bolivia. El mantenimiento de estos lazos, las prácticas transnacionales, son parte del modo de reproducción de estos colectivos. En ambos distritos, el transnacionalismo, las referencias cruzadas y simultáneas a los contextos de origen y destino, constituyen una clave fundamental para comprender la complejidad de los procesos de movilidad y las proyecciones de inclusión. 


\section{Transnacionalismo, territorio y movilidad: ¿conceptos que desafían el nacionalismo escolar?}

Nación y territorio constituyen una díada que ha marcado históricamente la concepción de los procesos formativos e identitarios en los contextos escolares. ${ }^{3} \mathrm{Si}$ bien los distintos sentidos del nacionalismo vienen siendo discutidos en las ciencias sociales desde hace años; entendemos que, en particular, la asociación entre nación y territorio debe ser problematizada en un contexto de creciente movilidad y porosidad de las fronteras. Esta problematización continúa pendiente en el sistema educativo.

Lo nacional, es una categoría clasificatoria del Estado, pero no se limita a ello: supone procesos, experiencias y sentimientos de pertenencia de amplios colectivos. Diversos autores advierten la necesidad de atender los significados que la ideología nacionalista adquiere para los diversos sectores sociales (Hobsbawn, 1991), los procesos de apropiación y resignificación que sufren los emblemas y símbolos nacionales (Anderson, 1993), la ambivalencia de la idea de nación (Bhabha, 2010; Chatterjee, 2008). Muchos de estos procesos resultan particularmente visibles en la población boliviana en Buenos Aires.

En esta población, las referencias nacionales coexisten y se articulan con las referencias étnicas, manifiestas sobre todo en los alineamientos de distintos grupos, el habla quechua, comidas, prácticas rituales, festividades, vestidos, música, danzas, etcétera. Estas características están presentes con más o menos intensidad en las prácticas que los "paisanos" de Bolivia asocian a "ser boliviano" en Escobar y en Ciudadela. La forma de vivir las adscripciones étnicas y nacionales, sin duda, es un componente importante para pensar el sentido del espacio, de los viajes, los constantes traslados que realiza la población entre Bolivia y Argentina, en definitiva, la condición transnacional.

Aunque la noción de transnacionalismo ha recibido cuestionamientos, creemos que resulta útil para analizar las trayectorias de los colectivos con los que trabajamos, sus sentimientos y proyecciones entre Bolivia y Argentina. En particular, la noción de transnacionalismo resulta sugerente para cuestionar los paradigmas asimilacionistas con que ha sido abordada la problemática migratoria, sobre todo en el campo educativo. Siguiendo a Dietz (2012), el transnacionalismo desafía la linealidad con que se ha pensado el fenómeno migratorio y las proyecciones simples de integración. También tensiona la noción escolar de "identidad nacional", entendida como única y homogénea.

Para comprender esta lógica de interrelación entre lo que podríamos denominar "el allá y el acá" puede ser útil recurrir a autores que sostienen la necesidad de que los estudios articulen la dimensión local, nacional y transnacional. Esto ha dado lugar a sostenidos debates en torno a la necesidad de pensar los contextos más allá de los lugares concretos (García Castaño, Álvarez Veinguer, Rubio Gómez, 2011, p. 206). En este sentido, aporta también la noción de simultaneidad de Peggy Levitt. Con esta noción Levitt invita a comprender que “... los migrantes se encuentran situados en múltiples lugares lo que hace necesario un marco de investigación que supere los binarismos asimilación-transnacionalismo" (Levitt \& Glick Schiller, 2004, p. 61).

Este "pensar más allá" de los lugares nos remite a la noción de "movilidad". La movilidad reviste en este campo de análisis una importancia central. Si bien la movilidad espacial de la población no es un objeto de investigación novedoso, el llamado "giro de la movilidad" (mobility turn), que se inaugura en las postrimerías de la década de 1990 (Creswell, 2006; Urry, 2000), dio un nuevo impulso a este enfoque. En ese marco, las movilidades espaciales son concebidas como lentes que permiten indagar las dinámicas sociales y urbanas. Para el análisis de las dos localidades donde trabajamos resulta también sugerente
3. La Ley de Educación Nacional 26206 (2006) afirma en su Artículo 3: “La educación es una prioridad nacional y se constituye en política d Estado para construir una sociedad justa, reafirmar la soberanía e identidad nacional, profundizar el ejercicio de la ciudadanía democrática, respetar los derechos humanos y libertades fundamentales y fortalecer el desarrollo económico-social de la Nación". 
la noción de "territorios construidos por el movimiento" (Deleuze \& Guattari, 1994). Rita Segato (2007) sugiere considerar que en los procesos contemporáneos la noción de territorio como significante de identidad se desprende de sus anclajes materiales fijos y pasa a tener movilidad: con esto los escenarios de la comunalidad son también móviles. Las experiencias de "territorialidad" del colectivo con el que trabajamos vinculan el "acá" y el "allá". Esto nos permite pensar que las familias migrantes, de modos diversos y complejos, "llevan su territorio a cuestas". La movilidad aparece, entonces, no solo como una forma de seguir vinculado a Bolivia, sino también como un elemento distintivo de las formas de habitar este nuevo territorio; en este sentido la movilidad es un aspecto de indudable relevancia en los procesos de identificación y representación de la identidad.

En este punto el trabajo de Candau resulta sugerente para pensar cómo ciertas transformaciones sociales -tales como los desplazamientos territoriales bajo estudio- se asocian a la construcción de imágenes propias caracterizadas por una significativa continuidad, a través de las cuales los sujetos procuran crear una conciencia identitaria en situaciones donde la misma es cuestionada. Esta construcción de una identidad grupal se hace efectiva a través de la selección de símbolos posibles de reificación y acentuando la permanencia de un supuesto origen (Candau, 2008).

Los espacios donde trabajamos pueden en muchos sentidos ser definidos por lo que Giménez define como una franja transfronteriza, caracterizada por la interacción de actores portadores de culturas de diferente origen y convergencia de múltiples territorialidades, (2008). En este sentido recuperamos también el concepto de multiterritorialidad (Haesbaert, 2013) en tanto el mismo remite a las experiencias simultáneas de diferentes territorios.

Por otra parte, nos preguntamos si también aporta a la comprensión de los procesos que estudiamos la noción de cultura migrante, en tanto la misma refiere a situaciones donde la migración es uno de tantos viajes y los lazos con el país de origen no se diluyen. Con esta categoría algunos especialistas en la temática aluden a la práctica recurrente e instituida de movilidad, a situaciones habituales donde toda la familia organiza su proyecto de vida en función de la migración (Rivero Sierra, 2012).

Estas formas de vivir lo nacional, la movilidad y el territorio, creemos, siguen interpelando al sistema educativo, poniendo en tensión matrices de identificación nacional unívoca, nociones que fijan la población a los espacios, y presupuestos simplistas sobre la inclusión. A su vez, constituyen aspectos que, desde nuestro punto de vista, resulta imprescindible considerar desde un enfoque amplio y profundo de la interculturalidad, para habilitar un diálogo en torno a los significados de las prácticas que desarrollan los jóvenes cotidianamente en su entorno sociocultural. En esas experiencias puede evidenciarse el reconocimiento de su entorno en términos de espacio-territorio (simbólico y vivido), es decir, se hacen presentes núcleos de conocimiento y procesos de identificación expresados en la concepción de la espacialidad y el territorio que recrean la memoria individual y la historia cultural y social como colectivos (Melgarejo, 2007).

Así como para la población migrante la movilidad emerge como un elemento distintivo de las formas de habitar este nuevo espacio, la escolarización de los niños y jóvenes es una de las prácticas más claramente asociadas a la permanencia en un territorio.

4. Este punto se sostiene sobre todo con referencias a Escobar donde el trabajo en contextos familiares y comunitarios tiene varios años de desarrollo. Algunas de las precisiones del punto se basan en un texto previo (Novaro \& Trino Cazón, 2017). Las mismas fueron revisadas y completadas con lecturas, registros y reflexiones posteriores.

\section{Entre allá y acá}

... a veces las palabras se desequilibran. ¿Dónde está el peso mayor del estar allí, en el estar o en el allí? ¿En el allí -que sería preferible llamar un aquí- debo buscar 
primeramente mi ser? O bien, ¿en mi ser voy a encontrar primero la certidumbre de mi fijación en un allí? De todas maneras, uno de los términos debilita siempre al otro (Bachelard, 1957, p. 186)

\section{Permanencia y regreso}

La decisión migratoria y el traslado a Argentina "para quedarse" pueden considerarse como uno de muchos viajes o experiencias de movilidad. Como dijimos, la población de Lambertuchi y Ciudadela proviene mayormente (en el caso de Escobar) y en una proporción significativa (en el caso de Tres de Febrero) de la zona de Potosí. El departamento de Potosí en Bolivia, se caracteriza por ser una zona muy empobrecida, con una tasa de emigración muy alta, y poblados que han quedado relativamente vacíos. Gran parte de las personas con las que conversamos comentaron que el principal motivo de la migración fue la búsqueda de trabajo remunerado, "hay trabajo, pero no hay plata" fue un comentario recurrente. Viajes recientes a Bolivia nos mostraron amplios territorios devastados por la contaminación de las minas y la movilidad creciente entre las zonas rurales y urbanas.

Las historias familiares que nos relataron en Buenos Aires recuerdan la migración con dolor, aluden con congoja a la situación de pobreza en Bolivia y el vaciamiento de sus pueblos "solo quedaron los viejos"; abundan las anécdotas de sacrificio y sufrimiento en los primeros tiempos en Argentina. Desde estos sentimientos los sujetos se interrogan sobre el presente y en muchos casos proyectan también un futuro entre Bolivia y Argentina. Se reiteran comentarios sobre las propiedades de las viviendas y terrenos en Bolivia que se mantienen muchos años y a los que con regularidad procuran volver al menos un periodo.

Una vez instalados en Buenos Aires la tensión entre volver y quedarse es central y define una variedad de acciones y sentimientos. Muchos adultos expresan el deseo de volver, otros, afecto con el espacio que ahora se habita. En general, evocan a Bolivia con tristeza y términos que aluden al pasado, muchos expresan lo que implica como costo y también como rédito la vida entre allá y acá:

Después me quería volver, pero justo vino la crisis del 2001 y yo tenía patacones, y me quedé. Acá comida siempre hay. Siempre tiran verdura, esta tierra es riquísima. Quizás mi hija estudie en Bolivia, acá se echan a perder los chicos. [Hombre de mediana edad radicado en Escobar, migró hace más de diez años, es dueño de un comedor donde sirven "comida boliviana"] (registro, 2012)

En Argentina mis parientes encontraron trabajo y se sentían seguros, todos trabajaban en el campo, lo que es de cultivo, la agricultura, como hasta ahora. Y de ahí no... no volvimos más, tenemos algo con que mantenernos, seguir viviendo... Y ahora estamos acá, todos crecidos acá y [...] nos visitamos, compartimos... [Mujer joven nacida en Bolivia y radicada desde pequeña en la zona de Escobar, trabaja como maestra] (registro, 2012)

Acá es muy hostil, ando nerviosa... pero en Bolivia no es así..., yo no sé cómo, pero vives tranquilo, yo me voy de aquí, soy feliz, pero vivo aquí y estoy desesperada. Acá mucha gente no tenía casa, alquilan, yo les decía, háblense, compremos por hectárea..., júntense platita, no piensen la Argentina no más. ¿Qué pasa al día de mañana?, sus hijos van a ir a Bolivia, ¿van a ir al campo nuestros hijos?, van adonde hemos nacido. [Mujer adulta que llamaremos Marta, llegó a Argentina en el año 2000, dirige una organización de mujeres en Escobar, viaja frecuentemente entre Bolivia y Argentina, expresó reiteradamente su deseo de volver] (Registro, 2012) 
Las citas anteriores muestran cómo los proyectos de permanencia y de regreso aparecen atravesados y afectan las relaciones generacionales. Los familiares expresan la expectativa de que Bolivia siga siendo una referencia significativa en las identificaciones de los niños y jóvenes. En el mismo sentido podrían interpretarse múltiples discursos de los referentes de las organizaciones y prácticas comunitarias de estas localidades. Como decimos en un texto anterior, nominaciones tales como "bolivianos de segunda generación" (de uso frecuente en distintos espacios), condensando una referencia espacial -Bolivia- y una temporal generación-, resultan reveladoras de los dilemas con los que esta población proyecta las pertenencias nacionales de los niños y jóvenes en relación con un territorio (Novaro, 2013).

En las familias con muchos hijos, frecuentemente, se espera que alguno de ellos retorne. Esto suele implicar periodos de prueba allá, en ocasiones vinculadas al estudio o el trabajo. Sin embargo, el proyecto de retorno de muchos adultos, a menudo, choca con el presente de los jóvenes que proyectan su futuro en Argentina. Las palabras de Marta y de muchos más son elocuentes:

... no se puede obligar a los hijos, yo trato de obligar a mis hijos que se vuelvan, pero... no, no quieren venir "anda, mamá" me dicen, ¿entonces que me pasa a mí, irme sola y dejar a mis hijos o... quedarme aquí? ¿Dónde está la mayoría de mis hijos? Están acá cuatro, uno está en Bolivia. [Marta] (registro, 2012)

Yo me quiero volver, allá se vive más tranquilo. Acá ahora hay mucha violencia. Allá eso no pasa. Pero mis hijos no quieren, me dicen, andate vos. Cuando fueron allá no les gustaba, Iloraban, se querían volver para acá. Lo que pasa es que allá están en el campo trabajando, acá, la escuela, el ciber, la televisión, allá eso no hay. Ellos ya están acostumbrados... [Mujer mayor, trabaja en la feria de ropa de Escobar, vino a Argentina hace nueve años] (registro, 2010)

... después los chicos, de visita si quieren ir ellos... dicen "ahora vamos a ir para vacaciones" ya es otro ambiente. Por eso nosotros extrañamos allá... dicen mis hijos "no, no... irse a Bolivia, a visitar vamos, para ir a vivir no" [Mujer adulta de Escobar, vino a Argentina hace veintiséis años, todos sus hijos nacieron en Argentina] (registro, 2012)

Para mí, mira... si tengo que elegir, me quedaría acá, allá es como iría a visitar, porque... no sé, acá es como que crecí, estudié, como que me abrió las puertas ¿viste? y si vuelvo a Bolivia, es como que no soy nadie... es muy difícil volver... [Mujer joven de Escobar, trabaja como maestra, vino a la Argentina de muy pequeña] (registro, 2012)

La clave generacional resulta bastante evidente en los comentarios: adultos tensados entre volver o quedarse con sus hijos, distintas posiciones entre una generación que experimentó la migración y otra a la que se la narraron y recrearon, o para la cual la movilidad es un viaje de ida y vuelta, no una experiencia migratoria. En definitiva, las distintas formas y sentidos de la movilidad hablan de Bolivia como un territorio evocado, principalmente para los adultos, y un territorio experimentado por las nuevas generaciones, aunque estas experiencias se sostengan en vivencias del transitar y no del habitar y se refuercen permanentemente en los relatos de los adultos.

\section{Los viajes y las fiestas entre allá y acá}

Así como los proyectos de permanencia y de regreso remiten a territorios específicos y a experiencias de determinados espacios que atraviesan a muchas familias migrantes, los viajes emergen como experiencias de otro tipo, pero intrínsecamente relacionados. Los viajes periódicos de las familias migrantes nos invitan a pensar la movilidad como un proceso, a la vez, estructurado por y estructurante de los territorios y de las experiencias de quienes los habitan. 
Los viajes tienen relación con emprendimientos productivos y vínculos políticos entre uno y otro territorio, aspectos (en particular el primero) que han sido trabajados por muchos investigadores (Benencia, 2006; Magliano, 2013; Trpin \& Pizarro, 2017). Pero, además, hay otras prácticas sociales significativas atravesadas por la movilidad que no han recibido aún la misma atención en las investigaciones. Hemos visto en los testimonios la importancia del mantenimiento de los lazos familiares a través de recurrentes viajes, por ejemplo, en ocasión de los nacimientos y las muertes.

Nos llamó particularmente la atención cómo en las familias los viajes a Bolivia aparecen vinculados a la presentación de los niños nacidos en Argentina a los parientes que han quedado allá. Cuando estos viajes y presentaciones no se producen, en muchos casos se vive una sensación de falta o de deuda. El mismo nacimiento para muchos es motivo de traslado por miedo al parto en uno u otro país por diferencias en los modos de atención o posibilidad de apoyo de los parientes cercanos. También las muertes son ocasiones en que se refuerza la necesidad de volver. Cuando un pariente muere allá, el arreglo de los papeles y la recomposición de los vínculos familiares son motivo frecuente de viaje, también el homenaje al muerto: es posible que no se pueda viajar inmediatamente, pero se espera poder hacerlo para el 1 de noviembre para rendirle homenaje en su primer santo o en el primer aniversario de su muerte.

En textos anteriores nos hemos detenido en cómo las festividades y los preparativos para ellas, son también momentos en que el allá y el acá se enlazan (Novaro, 2018). En principio, resulta elocuente que las festividades de la Colectividad tanto en Escobar como en Ciudadela se definen a partir de las fiestas cívicas de Bolivia (6 de agosto por la independencia de Bolivia, 10 de noviembre por el levantamiento de Potosí). Otros acontecimientos también son festejados, como los aniversarios de distintas localidades de Bolivia, el día de la madre boliviana y el carnaval.

La preparación de los grupos de música y danza enlaza el allá y el acá. En muchos casos los trajes e instrumentos se mandan a pedir a alguien que viaja o se hacen pedidos especiales a fabricantes en Bolivia. Un lugar especial en las fiestas tiene la presencia de grupos bolivianos que viajan especialmente para el evento. En definitiva, las fiestas aparecen en ambas localidades como situaciones que definen momentos y espacios para expresar la condición binacional. La presencia de Bolivia en Argentina se refuerza en el despliegue de emblemas, estéticas, en la presencia de autoridades bolivianas (embajador y cónsul). La intención de visibilizar la presencia en Argentina y la apuesta por la permanencia se hacen evidentes en la profusión de símbolos nacionales argentinos, discursos de autoridades políticas locales (funcionarios municipales y, en ocasiones, provinciales) agradecimientos a la "generosidad de esta tierra". Tanto los sentidos de evocación de Bolivia como la expectativa de seguir habitando la Argentina tienen como interlocutores fundamentales a las nuevas generaciones.

La significación de Bolivia y Argentina, las características de los viajes, las fiestas y las múltiples prácticas que enlazan el allá y el acá, nos invitan a revisar y precisar la idea de movilidad. En torno a ella resulta elocuente, para cerrar este punto, recuperar la noción de movimiento de Ingold dado el énfasis que este autor otorga al "transitar entre":

Como las raíces que crecen, los devenires humanos no se mueven por una dura y prefabricada superficie [...]. Ellas más bien encuentran o empujan su paso a través del suelo $y$, al hacerlo, contribuyen a su siempre emergente textura. Este es el tipo de movimiento que [...] busca no conectar puntos o territorios predeterminados, sino más bien, en cada momento, seguir andando [...] un movimiento -o lo que es lo mismo, una relación- que no va entre, sino a lo largo de. (2012, p. 46) 
5. Este punto se sostiene fundamentalmente en registros de escuelas secundarias de Ciudadela.
En este sentido, resulta significativo el énfasis en la "entre-dad", es decir, la invitación de este autor a no preocuparnos excesivamente por "las orillas" para no perder de vista "el río".

Vemos así que en ambas localidades la relación de los migrantes bolivianos con los lugares que ahora habitan se construye teniendo presente el espacio que han dejado. De esta forma, la apropiación del nuevo espacio se realiza desde experiencias atravesadas por la movilidad y la referencia a Bolivia. El acá no puede pensarse sin el allá, el permanecer o habitar un determinado territorio, o el arraigo, no pueden comprenderse sin atender a la movilidad, a esa experiencia del espacio o de los espacios, que se despliega, precisamente, entre los dos polos de ese devenir.

La fuerte relación entre identidad y territorio en los espacios que trabajamos se hace evidente en el hecho de que la pertenencia nacional se marca a partir del nacimiento en un espacio que se ha dejado, pero al que -como rasgo de la identificación-se alude de manera permanente en el nuevo país de residencia (Novaro, 2014). Esto se traduce, entre otras prácticas, en la multiplicación de marcas y emblemas del país de origen en el nuevo espacio que se habita: fortalecimiento de organizaciones, concentración en determinados territorios, formas colectivas de apropiación y uso del espacio, iniciativas por crear dispositivos de atención a la salud e incluso "escuelas propias" del colectivo migrante. En este sentido, centrarnos en el acá no implica omitir el allá. Esta simultaneidad del allá y el acá marca las relaciones entre las distintas generaciones, proyectando que quienes han nacido y se han criado acá no olviden de dónde procede el colectivo al que se espera que sigan perteneciendo.

\section{Entre el adentro y el afuera: del transnacionalismo al nacionalismo escolar $^{5}$}

Dentro y fuera constituyen una dialéctica de descuartizamiento [...] Tiene la claridad afilada de la dialéctica del sí y del no que lo decide todo. Se hace de ella, sin que nos demos cuenta, una base de imágenes que dominan todos los pensamientos de lo positivo y de lo negativo. (Bachelard, 1957, p. 185)

Como hemos dicho previamente, así como la movilidad constituye uno de los elementos clave de la experiencia del territorio de los colectivos migrantes, la escolarización de los niños y jóvenes aparece fuertemente asociada a la permanencia y proyección en un lugar. Por otra parte, la presencia de las familias migrantes interpela a los espacios escolares, especialmente a la escuela secundaria, tensionando relatos fundantes del sistema educativo, aún vigentes, vinculados a la construcción de una identidad nacional orientada a fusionar lo diferente, que conviven con los discursos sobre el respeto a la diversidad cultural de más reciente data. En este sentido, podría pensarse que, desde sus orígenes, la escuela secundaria ha estado atravesada por una tensión entre ese afuera del cual quiere distinguirse, pero que la penetra, y ese adentro que se pretende, históricamente, homogéneo, ordenado y previsible (Dussel \& Caruso, 1999; Julia, 2001; Pineau, 2001). Esta tensión se reactualiza en diferentes contextos históricos brindándole a ese vínculo entre el afuera y el adentro características específicas que resulta relevante analizar. El trabajo de campo nos permitirá realizar una aproximación a los desafíos que las experiencias del territorio de los colectivos migrantes plantean a las instituciones educativas, tanto en el ámbito de las relaciones y los vínculos entre los actores escolares, como de los procesos de legitimación de saberes. Entendemos que ambas dimensiones constituyen aspectos claves de la configuración actual de las escuelas secundarias. 


\section{La escuela y el afuera}

En Lambertuchi y en Ciudadela ${ }^{6}$ resulta significativo que las escuelas más distantes al centro de las localidades y en situación más precaria (en infraestructura, estabilidad de los cargos docentes, matrícula, etcétera) son las que muchos identifican como "la escuela de los bolivianos":

Como vivo a seis cuadras del colegio, escuchaba el comentario "Ah, así que usted es docente ahí en la escuela de los bolivianos". Entonces yo decía, "sí, de los bolivianos, de los peruanos, de los argentinos, de los ucranianos". [Profesora de escuela de Ciudadela] (registro, 2018)

Como señala Domenech al analizar una escuela con características similares de la periferia urbana de la Ciudad de Córdoba, nombrada como "la escuela del fondo": "Esta denominación estigmatizante sintetiza la marginalidad/marginación espacial y la marginalidad/marginación social que está inscripta como marca en la escuela, grabada en las representaciones que circulan sobre ella tanto adentro como afuera" (Domenech, 2014, p. 173).

La contracara la constituyen las escuelas más cercanas al centro (Escobar) o a la avenida (Ciudadela), consideradas "mejores" o de "mejor categoría" en la jerarquía de las instituciones escolares. Resulta sugerente, que en estos casos el paso de los jóvenes por la escuela se emparente con una "experiencia migrante":

Allí [se refiere a las escuelas del centro de Escobar] los hacen sentir mal, acá no porque mayormente estamos nosotros, [...] cuando entré a primer grado, tenía mucho miedo, porque no tenía relación... o sea comunicación con los argentinos. Tenía miedo que por ahí... si alguien me... me trataba mal o me discriminaba, las cargadas no eran buenas, me quedó esa imagen de chiquita. Yo me sentía como que... había llegado recién. [Mujer joven que vive en Argentina desde muy pequeña, maestra en Escobar] (registro 2012)

Los registros recién compartidos ponen en evidencia ciertos rasgos de la tensión entre la experiencia transnacional de los jóvenes y los modos en que su presencia en las escuelas es marcada desde afuera, "la escuela de los bolivianos" y desde adentro, a través de la discriminación y estigmatización.

El afuera es también narrado por algunos actores escolares como aquello que otorga a ese adentro su carácter diverso, intercultural o transnacional:

\begin{abstract}
Si hablo de esta escuela específicamente es una escuela que tiene mucha diversidad porque es una escuela que está en el límite entre Ciudadela y Liniers, y en Liniers hay mucha gente de comunidad boliviana, peruana, paraguaya. Como que Liniers es un centro de varias culturas. Mayormente acá en la escuela vienen chicos bolivianos que los padres trabajan en los negocios que hay acá. Liniers se hizo culturalmente boliviana, si vas a los barrios ahí de Rivadavia, entrás un poquito, hay toda comunidad boliviana. Es como si fuera Bolivia en chiquito. [Preceptora de escuela secundaria de Tres de Febrero] (registro, 2018)
\end{abstract}

La ubicación espacial de la escuela en un contexto descrito como intercultural por las nacionalidades y las culturas de quienes lo habitan, asigna a los estudiantes y sus familias un papel clave: son ellos quienes no solo dan identidad al barrio, sino que hacen que esas identidades y experiencias penetren en la escuela, tensionando las fronteras entre aquello que las paredes de la institución pretenden, simbólica y espacialmente, separar.
6. En el caso de la escuela de Lambertuchi a la que vamos a referirnos, los registros escolares dan cuenta de que aproximadamente el cincuenta por ciento de alumnos pertenecen a familias bolivianas, en la escuela de Ciudadela el setenta por ciento.

7. Expresión utilizada por Czarny (2007) en su investigación sobre los sentidos de la escolaridad para los indios triqui migrantes en la ciudad de México. 
Si nos situamos entre ese adentro y ese afuera, observamos que las características de los espacios escolares, y los diálogos que estos entablan con el afuera (el barrio, las familias y sus experiencias, etcétera), también hablan de las experiencias del territorio habitado que allí se producen, reproducen y reconocen. En ambos barrios, las marcas transnacionales del lugar (carteles en lengua quechua, banderas bolivianas, nombres de negocios que hacen referencia a Bolivia, aromas de la comida, mercadería que se vende, etcétera) contrastan con el ascetismo de los espacios escolares, que tienden a carecer de referencias a la población boliviana. Este contraste se percibe, por ejemplo, en el caso de Ciudadela, por el hecho de que el edificio donde funciona la escuela secundaria y primaria está ubicado al lado de un jardín de infantes que tiene en su frente un enorme mural alusivo a Bolivia. En Escobar presenciamos una situación similar años atrás, cuando un mural con imágenes asociadas a Bolivia, que había sido pintado por la profesora de plástica y los alumnos en la puerta de uno de los establecimientos de nivel primario, fue blanqueado luego de que algunos docentes expresaran a los directivos: "esta no es la escuela de los bolivianos". Las paredes exteriores de las escuelas se muestran en ambos casos como lugares especialmente significativos, en tanto en ellas las instituciones definen la imagen que quieren "mostrar hacia el afuera".

\section{Miradas desde adentro}

$\mathrm{Al}$ interior de los espacios escolares, las experiencias del territorio de los jóvenes y sus familias también se hacen presentes, ya sea en el modo de habitar la escuela o en las formas en que docentes, preceptores y directivos reconocen, invisibilizan o niegan las experiencias del afuera, tanto en el contexto del aula como en otras situaciones escolares.

Algunos indicios de las experiencias del territorio en el interior de los espacios escolares se registran en la organización de los tiempos y el calendario escolar. Muchas familias que trabajan en la frutihorticultura, a partir de los meses de abril-mayo cuando el trabajo disminuye en la quinta, viajan a Bolivia junto con sus hijos y retornan antes de agosto (Trino Cazón, 2016); otras solicitan que se les cierren antes las notas para poder viajar en noviembre-diciembre. La ausencia de los chicos asociadas a los viajes (por el trabajo en la cosecha, trámites en Bolivia, enfermedades de parientes) es vivida, en ciertos casos, como una falta, "vienen cuando quieren", o es experimentada como un problema para el desarrollo de su aprendizaje: "El que falta más de tres veces o empezó un mes más tarde no va a aprobar el primer trimestre" (Registro de campo, mayo 2018, Tres de Febrero). Así, cuando el espacio dejado se hace presente en las escuelas por la necesidad de volver a Bolivia, emerge una situación que evidentemente crea desajustes con la dinámica escolar tradicional y desafía las concepciones legitimadas de trayectoria escolar. En muchos casos, este desafío más que estimular la búsqueda de salidas, termina en la condena a la población (Novaro \& Trino Cazón, 2017). En la escuela de Ciudadela, sin embargo, docentes y directivos han manifestado que ya están "acostumbrados" a estos viajes y que se acompaña la trayectoria de estos estudiantes "desde otro formato" (Entrevista a directivo, junio 2018, Tres de Febrero):

Yo, al menos, tengo en cuenta el tema de los viajes porque son chicos que, pasa algo con familiares de allá, porque tienen sus abuelos o mismo sus papás porque vinieron con algún tío, y ellos tienen que viajar [...] y se les justifica la falta, está contemplado. [Preceptora de escuela secundaria de Ciudadela] (Registro, 2018)

Los festejos constituyen otra ocasión en la cual el adentro interactúa con el afuera. En ellos se registran tensiones para sostener espacios de encuentro y reconocimiento que superen el presupuesto de la identificación con una única nacionalidad. Si bien las referencias a la identidad de los jóvenes bolivianos o descendientes suelen relegarse al 
"Día del Respeto a la Diversidad Cultural" o al "Día de la Tradición" y adoptar formas folclorizadas, aquí también comenzamos a observar intentos significativos de abordar la interculturalidad desde otros enfoques.

En las escuelas, el aula sigue siendo el lugar primordial en el cual las situaciones instituidas de enseñanza y aprendizaje acontecen, allí lo nacional y lo transnacional también adoptan formas particulares. En el marco de diversas clases de Ciencias Sociales hemos podido observar una tendencia a trabajar las problemáticas sociales, y específicamente geográficas, en función de casos y ejemplos que los estudiantes manifestaron como desconocidos o ajenos y que tienden a hacer una valoración positiva de Europa (y Estados Unidos), negativa de América Latina y alusiones positivas a la migración transatlántica. En situaciones de clase registramos, por ejemplo, menciones a la contaminación de los canales de Venecia y su limpieza, las prácticas de reciclado en Estados Unidos, etcétera. La recurrencia de estos ejemplos, y la falta de interpelación a las experiencias y saberes de los estudiantes, nos sugieren cierta persistencia en los docentes de sistematizaciones conceptuales tradicionales de las ciencias sociales que tienden a impedir el reconocimiento de saberes de los alumnos construidos en ámbitos de pertenencia sociocultural (Trigo, Rotondaro, Flores \& Flouch, 2014. También dan cuenta de la connotación positiva que históricamente ha tenido la inmigración transatlántica en el currículum escolar. Es decir que las experiencias del territorio, del afuera, también son jerarquizadas y valoradas diferencialmente en el espacio escolar.

En otras clases, que consistieron en el copiado de definiciones del pizarrón (como la que incluimos a continuación), advertimos el trabajo con nociones de "frontera" muy distantes de concepciones que permitan pensar los mismos barrios de Escobar y Ciudadela como espacios de frontera, como imagen de distancia, pero también de encuentro:

La frontera: es la franja de territorio que se encuentra a ambos lados del límite internacional. Su ancho es variable y depende de la influencia que recibe un país del otro. Es la zona de intercambio cultural (el idioma, costumbres, músicas, vestimentas, comidas típicas y religión).

Frontera de separación: la relación con los países vecinos es mayor por la cadena montañosa o un río. Es el caso de nuestro país con Chile.

Fronteras abiertas o de contacto: se produce un verdadero intercambio comercial y económico para ambos países. Es el caso de nuestra frontera con Brasil, Paraguay, Uruguay y Bolivia... [carpeta de $5 .^{\circ}$ año, materia Geografía] (Registro, 2018)

La propuesta de trabajo, consistente en el copiado y control de lectura de fotocopias del manual, no habilitó intercambios ni el surgimiento de tensiones o la puesta en juego de las experiencias de los jóvenes, pues se redujo a las definiciones propuestas por la docente basadas, a su vez, en el libro de texto. La actitud de los estudiantes en esta situación áulica estuvo signada por la búsqueda de la respuesta esperada por la docente más que por la problematización de los contenidos y enfoques propuestos.

Para complejizar el análisis de estos aspectos debemos tener en cuenta que, en las escuelas secundarias de la provincia de Buenos Aires el mandato acerca de cómo conceptualizar y enseñar las nociones de espacio, frontera, límite y nación fue revisado durante la primera década del siglo XXI. A partir de entonces, los Diseños Curriculares de Ciencias Sociales de la provincia de Buenos Aires para la escuela secundaria prescriben una concepción del espacio entendido como construcción social (enunciado que desde hace algunos años forma parte de un discurso más amplio que ha renovado la 
8. En el Diseño Curricular de Geografía de 4.0 año se mencionan los siguientes temas, que se propone abordar con foco en los continentes de África y Europa: “Las cadenas migratorias. La libre circulación del capital a escala mundial y las barreras

a los desplazamientos poblacionales por razones laborales. Cambios y continuidades en las migraciones. Las razones económicas y políticas; individuales y sociales; y la dirección de los desplazamientos. La xenofobia, la inserción precaria en el mundo del trabajo y la segregación social y/o urbana que afecta a los migrantes. La relevancia del inmigrante en las estructuras sociodemográfica nacionales. Las organizaciones sociales que nuclean a los migrantes". Otros temas como, "El arraigo y el desarraigo de los migrantes en las actuales ciudades grandes, medianas y pequeñas", forman parte del Diseño Curricular de 6.0 año. geografía escolar desde al menos la segunda mitad de la década de 1980 y más plenamente desde mediados de los años noventa) y un concepto de "espacialidad humana" que pone el énfasis en el espacio como "una dimensión estructurante y organizativa de la vida social dinamizada por determinados sujetos sociales" (Buenos Aires/DGCyE, 2006, p. 63-64). Entre las materias del área de ciencias sociales de los años superiores también es posible encontrar contenidos que dan cuenta de la centralidad de la problemática migratoria. ${ }^{8}$ Nuestros registros dan cuenta de que en muchas ocasiones estas temáticas, saberes y enfoques no necesariamente se hacen presentes en las aulas. Sin embargo, junto con las prácticas áulicas ya mencionadas también hemos registrado importantes esfuerzos por trabajar desde diferentes materias con un enfoque intercultural que, si bien aparece como difuso, ha brindado a los estudiantes la oportunidad de crear proyectos donde sus experiencias se han hecho presentes. Mencionaremos algunos de ellos a continuación.

En una de las escuelas, en un evento conocido como la "Maratón de Lectura" los estudiantes elaboraron escritos autobiográficos, que luego fueron leídos en un evento escolar:

Comenzamos el viaje. Yo no sabía qué cambiaría, no pensé nunca que haría un viaje de semejante magnitud, no sabía cómo sería esa Argentina de la que tanto se hablaba. Mi mamá ya había hecho el viaje antes, pero nunca me había contado cómo era. Ella no estaba emocionada; mientras más cerca estábamos más triste parecía... [Estudiante de $5 .^{\circ}$ año, “Conociendo la verdad”, Ciudadela] (Registro, 2018)

En diversos intercambios con los sujetos involucrados en este evento se relevó que, aquello que primó en el recuerdo fue un baile boliviano realizado por un grupo de estudiantes, es decir, la interpelación folclorizada de la cultura de los jóvenes; no obstante, la circulación de este tipo de relatos autobiográficos en los espacios escolares augura la posibilidad de otros diálogos entre la cultura escolar y las experiencias del territorio de los jóvenes.

Incluso en una feria de fin de año, un grupo de estudiantes representó su mirada acerca de la interculturalidad a través de una performance en la cual el desplazamiento de sus cuerpos en el espacio jugó un rol crucial para dar cuenta de encuentros, tensiones, interrelaciones y desencuentros. A modo de presentación, comentaron que la propuesta consistía en "representar un sinfín de culturas a entender a base de abrazos y caminos entrecruzados" [Feria Escolar Anual, Ciudadela] (Registro, 2018). Esta representación espacial y corporal de la interculturalidad, creada e interpretada por los mismos jóvenes, aparece como un valioso intento de habilitar otras formas de vinculación con el entorno y con las experiencias de la población migrante.

Las situaciones registradas dan cuenta de la alternancia de posiciones, la intención de replantear mandatos y los límites para hacerlo. El mandato asimilacionista que sigue atravesando a la escuela y que se expresa en una diversidad de situaciones que hemos analizado a lo largo de este apartado parece bastante difícil de compatibilizar con una perspectiva amplia de inclusión social y educativa y la valoración de la condición transnacional de la vida de los jóvenes. Sin embargo, en las relaciones cotidianas de las escuelas donde trabajamos registramos valiosos intentos de reformular las formas de vinculación con el entorno, por ejemplo, a través de sostenidos esfuerzos por lograr otras formas de diálogo y presencia con la población migrante. La escuela secundaria se sigue debatiendo en su vínculo con un afuera, que se advierte como externo, diverso y complejo, pero que la atraviesa y la impulsa a asumir nuevos desafíos. 


\section{Conclusiones}

A lo largo de este trabajo hemos abordado las experiencias del territorio entre migrantes provenientes de Bolivia que habitan dos localidades de la provincia de Buenos Aires, realizamos luego un contrapunto con las representaciones y experiencias del territorio en las escuelas de la localidad. El territorio es concebido como producción social apropiada, trazada, recorrida, delimitada y marcada por procesos de identificación. La relación con el territorio, en tanto aspecto donde se despliegan posicionamientos y proyectos en clave generacional, interpela las experiencias y mandatos educativos.

La forma de vivir las adscripciones étnicas y nacionales constituyó un componente importante para pensar el sentido del espacio, de los viajes, los constantes traslados que realiza la población entre Bolivia y Argentina.

Las categorías "espacio dejado" y "espacio habitado", construidas a la luz de las notas de campo, es decir, del registro de las experiencias y comentarios sobre los espacios transitados por la población migrante, nos remitieron a la condición transnacional de sus proyectos y sus referencias de identificación. Estos espacios experimentados, transitados y representados emergen en los discursos haciendo referencia a un "alla" (Bolivia) y un "acá" (Argentina). Inspirándonos en Bachelard, analizamos estos términos como una geometría que inevitablemente desplaza el énfasis hacia uno de sus extremos. El análisis de estos vértices (acá y allá), sin embargo, no resultó suficiente para dar cuenta de aquello que intentamos pensar. Los viajes, las fiestas y ciertos aspectos de la vida cotidiana nos plantearon la necesidad de detenernos en el "transitar entre" (Ingold, 2012), es decir, en la movilidad. La noción de "territorialidad" entendida como experiencia particular, histórica y culturalmente definida del territorio (Segato, 2007) nos permitió vincular el "acá" y el "allá", y pensar en los modos en los cuales las familias migrantes, de modos diversos y complejos, llevan su territorio a cuestas o construyen, en su movimiento, territorios propios.

Los proyectos de permanencia y de regreso aparecen atravesados y afectan las relaciones generacionales. Los familiares y referentes de las organizaciones expresan la expectativa de que Bolivia siga siendo una referencia significativa en las identificaciones de los niños y jóvenes. Esta referencia también se expresa en marcas territoriales que permitieron comenzar a pensar en los barrios en los cuales trabajamos en términos de territorios bolivianos (o en gran medida bolivianos) en Argentina, espacios físicos donde la población migrante desarrolla sentidos de colectividad. En el mismo sentido referencial podrían interpretarse múltiples prácticas familiares y comunitarias de estas localidades que entran en tensión con concepciones y prácticas escolares que insisten en reforzar nociones tradicionales y unívocas de nación, frontera y territorio.

El análisis de los desafíos que las experiencias del territorio de los colectivos migrantes plantean a las instituciones educativas se focalizó tanto en el ámbito de las relaciones y los vínculos entre los actores escolares, como de los procesos de legitimación de saberes. Buscamos tensionar el binomio adentro-afuera que sigue latente y que ha estructurado históricamente la relación de la escuela con aquello que la rodea y que pretende externo. En la misma línea, observamos que el carácter transnacional de la población que asiste a las escuelas desafía modelos de identificación unívocos y modos de organización escolares, que, incluso luego de años de convivencia con mandatos y retóricas de diversidad e interculturalidad, siguen dificultando la comprensión del carácter múltiple de las identificaciones nacionales de amplios sectores de la población escolar. 
Las características de los espacios escolares, los modos en que los estudiantes los habitan, las propuestas áulicas de los docentes y las concepciones de territorio, nación y frontera dan cuenta del largo camino que aún resta recorrer para la consolidación de prácticas que efectivicen la inclusión social y escolar de los jóvenes de los colectivos migrantes. A partir del recorrido realizado en el texto creemos posible sostener que esta inclusión (en los vínculos y en los conocimientos escolares) supone considerar tanto las experiencias de movimiento hacia y desde Bolivia, como el modo en que los jóvenes habitan y transitan los espacios comunitarios y escolares en Argentina. 


\section{- Referencias bibliográficas}

"Anderson, B. (1993). Comunidades imaginadas. Reflexiones sobre el origen y la difusión del nacionalismo. México: Fondo de Cultura Económica.

»Benencia, R. (2006). Inserción de inmigrantes bolivianos y mercado de trabajo rural argentino. Familias transnacionales en la conformación de territorios productivos. Geodemos, (11), 17-38.

»Bhabha, H. (comp.). (2010). Nación y narración. Entre la ilusión de una identidad y las diferencias culturales. Buenos Aires: Siglo Veintiuno.

»Candau, J. (2008). Memoria e identidad. Buenos Aires: Del Sol.

" Cerruti, M. \& Binstock, G. (2012). Los estudiantes inmigrantes en la escuela secundaria. Integración y desafíos. Buenos Aires: Fondo de las Naciones Unidas para la Infancia.

»Chatterjee, P. (2008). La nación en tiempo heterogéneo y otros estudios subalternos. Buenos Aires: Siglo Veintiuno - Clacso.

"Creswell, T. (2006). On the Move: Mobility in the Modern Western World. Londres: Routledge.

»Czarny, G. (2007). Pasar por la escuela: metáfora que guarda distintas caras para abordar la relación comunidades indígenas y escolaridad. Revista Mexicana de Investigación Educativa. XII(34), 921-950.

»Deleuze, G. \& Guattari, F. (1994). Mil mesetas. Capitalismo y esquizofrenia. Valencia: Pre-textos.

»Dietz, G. (2012). Multiculturalismo, interculturalidad y diversidad en educación. Una aproximación antropológica. México: Fondo de Cultura Económica.

»Dirección General de Cultura y Educación de la Provincia de Buenos Aires (2006). Diseño Curricular para la Educación Secundaria: 1a año ESB. Ariel Zysman y Marina Paulozzo (cords.) 2a ed. La Plata.

»Domenech, E. (2014). “Bolivianos" en la “escuela argentina”: representaciones acerca de los hijos de inmigrantes bolivianos en una escuela de la periferia urbana. REMHU, año XXII, (42), 171-188. Brasilia.

»Dussel, I. \& Caruso, M. (1999). La invención del aula. Una genealogía de las formas de enseñar. Buenos Aires: Santillana.

»García Castaño, J.; Álvarez Veinguer, A; Rubio Gómez, M. (2011). Prismas transescalares en el estudio de las migraciones. Revista de Antropología Social (20), 203-228.

" Giménez, G. (2008). Cultura, identidad y memoria. Materiales para una sociología de los procesos culturales en las franjas fronterizas. Frontera Norte, 21(41), 7-32.

» Haesbaert, R. (2013). Del mito de la desterritorialización a la multiterritorialidad. Cultura y representaciones sociales, año 8, (15).

» Hecht, C., García Palacios, M, Enriz, N y Diez, M. L. (2015). Interculturalidad y educación en Argentina: reflexiones a propósito de un concepto polisémico. 
En Novaro, G., Padawer, A. \& Hecht, C. (coords.), Educación, pueblos indígenas y migrantes. Reflexiones desde México, Brasil, Bolivia, Argentina y España. Buenos Aires: Biblos.

» Hobsbawn, E. (1991). Naciones y nacionalismo desde 1780. Barcelona: Crítica.

"Ingold, T. (2012). Ambientes para la vida. Conversaciones sobre humanidad, conocimiento y antropología. Montevideo: Trilce.

" Julia, D. (2001). A cultura escolar como objeto histórico. Revista Brasileira de História da Educação, (1).

" Levitt, P. \& Glick Schiller, N. (2004). Perspectivas internacionales sobre migración: conceptuar la simultaneidad. Migración y Desarrollo, (3), 60-91.

" Magliano, M. J. (2013). Los significados de vivir “múltiples presencias”: Mujeres bolivianas en Argentina. Migraciones internacionales, 7, 165-195.

» Melgarejo, P. (2007). Nuestros calendarios y mapas cuentan nuestra historia. Tiempo y espacio: Diálogos entre voces indígenas y escuela. México, Universidad Pedagógica Nacional.

» Novaro, G. (2013). Migración y Educación. Procesos de inclusión y exclusión educativa de niños migrantes. En Karasik, G. A. (coord.), Migraciones internacionales, pp. 209-230. Buenos Aires: CICCUS.

$»$ _ (2014). Procesos de identificación nacional en población migrante: continuidades y quiebres en las relaciones intergeneracionales. Revista de Antropología Social, Universidad Complutense de Madrid (23): 157-179.

»_...(2015). Familias, asociaciones y escuelas: tensiones en las identificaciones nacionales de niños migrantes. Linhas Críticas, (21), 77-93. Facultad de Educación de la Universidad Nacional de Brasilia.

"__. (2016). Migración boliviana, discursos civilizatorios y experiencias educativas en Argentina. Nómadas (45). Colombia.

"_. (2018). Dances in migratory, community and school contexts: identity marks and folklorised presences. Ethnography and Education (13), 340-358.

» Novaro, G. \& Diez, M. L. (2011). ¿Una inclusión silenciosa o las sutiles formas de la discriminación? Relexiones a propósito de la escolarización de chicos bolivianos. En Courtis, C. \& Pacecca, M. I. (comps.), Discriminaciones étnicas y nacionales. Buenos Aires: Del Puerto.

» Novaro, G. \& Trino Cazón, M. K. (2017). Viajes, organizaciones y escuelas: experiencias transnacionales de migrantes bolivianos en dos localidades de Buenos Aires. En De Cristóforis, N. \& Novick, S., Jornadas Un siglo de migraciones en la Argentina contemporánea: 1914-2014, pp. 579-597. Buenos Aires: Instituto de Investigaciones Gino Germani.

»Pineau, P. (2001). ¿Por qué triunfó la escuela?. En Pineau, P., Dussel, I. \& Caruso, M., La escuela como máquina de educar. Buenos Aires: Paidós.

»Pizarro, C. (2007). “Inmigración y discriminación en el lugar de trabajo. El caso del mercado frutihortícola de la colectividad boliviana de Escobar". Revista Estudios Migratorios Latinoamericanos, 21(63): 211-244.

»Trpin, V. \& Pizarro, C. (2017). Movilidad territorial, circuitos laborales y desigualdades en producciones agrarias de argentina: abordajes interdisciplinares y debates conceptuales. REMHU, 25(49), 35-58. Brasilia. 
»Rivero Sierra, F. (2012). Cultura migratoria y condiciones de emigración en comunidades campesinas de Toropalca. Potosí, Bolivia. Recuperado de: https:// dialnet.unirioja.es/descarga/articulo/4422981.pdf

"Segato, R. (2007). La Nación y sus otros. Buenos Aires: Prometeo.

"Thisted, S. (2014). Políticas, retóricas y prácticas educativas en torno a la cuestión de las “diferencias”. En Villa, A. I. \& Martínez, M. E. (comps.), Relaciones escolares y diferencias culturales: la educación en perspectiva intercultural. Buenos Aires: Noveduc.

» Trigo, L., Rotondaro, A., Flores, N. \& Flouch, A. (2014). Reflexión y acción en torno a la interculturalidad: cambios y resistencias en el pensamiento de profesores de Geografía que trabajan con alumnos pertenecientes a sectores populares. Trabajo presentado en III Coloquio Internacional de Didáctica de la Geografía. REDLAGEO-INDEGEO-UBA.

»Trino Cazón, M. K. (2016). La Participación de las familias de origen boliviano en una Escuela Primaria del Gran Buenos Aires. [Tesis de grado]. Universidad Nacional de Luján. Luján, Buenos Aires, Argentina.

»Urry, J. (2000). Sociology beyond Societies. Londres: Routledge.

\section{Bibliografía de consulta}

"Diez, M. L. \& Novaro, G. (2014). Continuidades y discontinuidades entre sistemas educativos nacionales: la educación en Bolivia y en Argentina desde una perspectiva intercultural. En Villa, A. \& Martínez, M. E. (comps.), Relaciones escolares y diferencias culturales: la educación en perspectiva intercultural (pp. 199-230). Buenos Aires, Noveduc.

"Diez, M. L., Novaro, G. \& Fariña, F. (2015). Para aprender a hacer, tenés que hacerlo, pero si podés estudiar mejor: migración, experiencias formativas y apuestas identitarias intergeneracionales. Actas XI Reunión de Antropología del Mercosur. Montevideo, Uruguay.

"Escobar Basabilbaso, M. \& Di Nucci, J. (2012). Circuitos de la economía urbana en la Ciudad de Buenos Aires: el comercio étnico de la colectividad boliviana en el barrio de Liniers. Estudios Socioterritoriales, (12), 99-122.

» Gavazzo, N. (2011). Acceso diferencial a la ciudad. Identificaciones y estereotipos entre los hijos de inmigrantes bolivianos y paraguayos en Buenos Aires. Social and Spatial Inclusion of International Migrants. Paper Series, (8). Recuperado de: www.unescochair-iuav.it

"Grimson, A. (1999). Relatos de la diferencia y la igualdad. Los bolivianos en Buenos Aires. Buenos Aires: Eudeba.

» Groisman, L. \& Hendel, V. (2017). Interpelaciones identitarias y efectivización del derecho a la educación de jóvenes migrantes en contextos escolares de la Argentina. Crítica Educativa, São Carlos.

"Ingold, T. (2000). La percepción del ambiente. Londres: Routledge.

"Mallimaci Barral, A. I. (2007). Hacerse comunidad. Construcciones del espacio boliviano en Ushuaia. Trabajo presentado en VII Jornadas de Sociología. Facultad de Ciencias Sociales, UBA, Buenos Aires, Argentina. 
» Mera, G. (2013). Pensar las categorías, pensar el Estado. Reflexiones en torno al concepto de segregación espacial de los migrantes. En Karasik, G. A. (coord.), Migraciones internacionales. pp. 143-16o. Buenos Aires: CICCUS.

» Rivero Sierra, F. (2008). Ni Tinku, ni saya, ni kullaguada: la práctica del fútbol como práctica cultural boliviana en Lules, Tucumán. Trabajo presentado en IX Congreso de Antropología Social. Misiones, Argentina.

"Sassone, S. \& Mera C. (2007). Barrios de migrantes en Buenos Aires: Identidad, cultura y cohesión socioterritorial. Trabajo presentado en V Congreso Europeo CEISAL de Latinoamericanistas. Bruselas, Bélgica.

"Sayad, A. (2010). La doble ausencia. De las ilusiones del emigrado a los padecimientos del inmigrado. Barcelona: Anthropos.

\section{Verónica Hendel}

Doctora en Ciencias Sociales y Profesora y Licenciada en Sociología por la Universidad de Buenos Aires. Investigadora asistente del Consejo Nacional de Investigaciones Científicas y Técnicas (Conicet) con sede en el Área de Estudios Interdisciplinarios en Educación Aborigen de la Universidad Nacional de Luján. Luján, Argentina. Correo electrónico: vero_hendel@yahoo.com

\section{Gabriela Novaro}

Doctora en Ciencias Antropológicas por la Universidad de Buenos Aires (UBA) e Investigadora Independiente del Consejo Nacional de Investigaciones Científicas y Técnicas (Conicet). Profesora de Antropología en la Facultad de Filosofía y Letras de la UBA, Buenos Aires, Argentina. Desde el año 2004 dirige proyectos sobre interculturalidad y educación financiados por la Universidad de Buenos Aires (UBA), el Conicet y la Agencia Nacional de Promoción Científica y Tecnológica. Correo electrónico: gabriela.novaro@gmail.com 